\title{
Comparative efficacy, acceptability, and tolerability of dexmethylphenidate versus placebo in child and adolescent ADHD: a meta-analysis of randomized controlled trials
}

\author{
This article was published in the following Dove Press journal: \\ Neuropsychiatric Disease and Treatment \\ 25 November 2015 \\ Number of times this article has been viewed
}

\author{
Narong Maneeton ${ }^{1, *}$ \\ Benchalak Maneeton ${ }^{1, *}$ \\ Pakapan Woottiluk ${ }^{2}$ \\ Sirijit Suttajit ${ }^{\prime}$ \\ Surinporn Likhitsathian' \\ Chawanun Charnsil' \\ Manit Srisurapanont ${ }^{1}$ \\ 'Department of Psychiatry, Faculty \\ of Medicine, ${ }^{2}$ Division of Psychiatric \\ Nursing, Faculty of Nursing, Chiang \\ Mai University, Chiang Mai, Thailand \\ *These authors contributed equally to \\ this work
}

Background: The efficacy of dexmethylphenidate (d-MPH) has been proven in the treatment of children and adolescents with attention-deficit hyperactivity disorder (ADHD).

Objective: The aim of this systematic review is to determine the efficacy, acceptability, and tolerability of d-MPH in child and adolescent ADHD.

Methods: The searches of SCOPUS, MEDLINE, CINAHL, and Cochrane Controlled Trials Register were performed in February 2015. All randomized controlled trials of d-MPH versus placebo that were performed in children and adolescents with ADHD up to 18 years of age were included in the study. The efficacy was measured by using the pooled mean-endpoint or mean-changed scores of ADHD rating scales and the response rate. Acceptability and tolerability were measured by using the pooled rates of overall discontinuation and discontinuation due to adverse events, respectively.

Results: A total of 1,124 children and adolescents diagnosed as having ADHD were included in this review. In a laboratory school setting, the pooled mean-change and mean-endpoint scores in the d-MPH-treated group were significantly greater than those of the placebo-treated group with standardized mean difference (95\% confidence interval $[\mathrm{CI}])$ of $-1.20(-1.73,-0.67)$, $I^{2}=95 \%$. Additionally, the pooled mean-changed scores of the ADHD rating scales for teachers and parents in the d-MPH-treated group were significantly greater than that of the placebotreated group with weighted mean difference $(95 \% \mathrm{CI})$ of $-13.01(-15.97,-10.05), I^{2}=0 \%$ and $(95 \% \mathrm{CI})$ of $-12.99(-15.57,-10.42), I^{2}=0 \%$, respectively. The pooled response rate in the d-MPH-treated groups had a significance higher than that of the placebo-treated group. The rates of pooled overall discontinuation and discontinuation due to adverse events between the two groups were not significantly different.

Conclusion: Based on the findings in this review, it can be concluded that d-MPH medication is efficacious and tolerable in child and adolescent ADHD. However, the acceptability of d-MPH is no greater than that of the placebo. Further systematic studies may confirm these findings.

Keywords: dexmethylphenidate, child and adolescent ADHD, meta-analysis

\section{Background}

Attention-deficit hyperactivity disorder (ADHD) is a commonly diagnosed behavioral disorder in children and adolescents. Its prevalence rate ranges from 5\% to $10 \%{ }^{1-3}$ In addition to hyperactivity, impulsivity, and inattention, children and adolescents usually encounter impairment of executive function, which may affect behavior and academic achievement. ${ }^{4}$ Thus, appropriate intervention in those patients may decrease the incidence of such problems.
Correspondence: Narong Maneeton Penchiatry, Faculty II 0 Intawaroros Road, Sriphum, Amphur Muang, Chiang Mai 50200,

Thailand

Tel +6653935422

Fax +6653935426

Email narong.m@cmu.ac.th 
Until now, pharmacotherapy has been the treatment of choice for ADHD. Although nonstimulants have shown their efficacy in the treatment of $\mathrm{ADHD},{ }^{5-7}$ they have been used as alternative treatments for ADHD. Psychostimulants are efficacious and indicated as the first-line drug in the treatment of children and adolescents with ADHD. ${ }^{8,9}$ A racemic $\mathrm{D}, \mathrm{L}-\mathrm{methylphenidate} \mathrm{hydrochloride} \mathrm{has} \mathrm{been}$ proved to be effective and has been widely prescribed for ADHD. ${ }^{10-12}$ Dexmethylphenidate (d-MPH) hydrochloride is a D-threo enantiomer of racemic D,L-methylphenidate with an approximately tenfold greater potent pharmacological effect than L-methylphenidate. ${ }^{13}$ After oral administration, d-MPH does not racemize; therefore, it is possible for it to reach similar efficacy at approximately half the dose of racemic D,L-methylphenidate. ${ }^{14}$

Recent evidence indicates that d-MPH is an efficacious and well-tolerated medication in the treatment of child and adolescent ADHD. Several randomized controlled trials (RCTs) have established d-MPH as a promising medication in terms of efficacy and tolerability in such patients. ${ }^{14-24}$ Since the number of subjects in those RCTs was small, metaanalysis, which determines more efficiently the true effective size and which includes all the subjects of those studies, should be the appropriate assessment method to evaluate the efficacy, acceptability, and tolerability of d-MPH in the treatment of child and adolescent ADHD.

In this meta-analysis, we systematically reviewed the efficacy of d-MPH versus placebo in the treatment of children and adolescents with ADHD. In addition, the acceptability and tolerability were also determined.

\section{Methods}

Although the Food and Drug Administration approved $\mathrm{d}-\mathrm{MPH}$ for the treatment of ADHD in November $2001,{ }^{25}$ the first publications of d-MPH in the PubMed appeared in 2002. Therefore, searching for relevant clinical studies commenced in January 2002 and continued until February 2015.

\section{Eligibility criteria}

Any RCT of methylphenidate conducted in children and adolescents with ADHD spectrum and reporting scores of standardized ADHD rating scales was eligible for this review. Additionally, both the rate of response and the rate of discontinuation had to be illustrated. The minimum sample size for each trial was not limited. The ADHD spectrum was composed of ADHD, attention-deficit disorder, hyperkinetic syndrome, hyperkinetic reaction, and hyperkinetic conduct disorder diagnosed by any set of criteria. However, any study of ADHD with comorbidity was excluded from this review. Gathered from the search terms in English, trials in any language were eligible for analysis.

\section{Information sources}

Searching, confined to only manual searching, was conducted mainly in SCOPUS, MEDLINE, CINAHL, Cochrane Controlled Trials Register databases, ClinicalTrials.gov, EU Clinical Trials Register (EU-CTR), and the database of a drug company producing original d-MPH, in February 2015. The references of the articles obtained by all means were also searched. Only relevant RCTs and controlled clinical trials (CCTs) were considered eligible in this meta-analysis.

\section{Searches}

To increase the sensitivity for identifying the RCTs and CCTs, a strategic search was carried out using a combination of the following words and phrases: ([dexmethylphenidate] OR [Focalin]) AND ([attention-deficit hyperactivity disorder] OR [ADHD] OR [attention-deficit disorder] OR [hyperkinetic syndrome] OR [hyperkinetic reaction]). This approach was applied in searching all the databases.

\section{Study selection}

The authors (NM and $\mathrm{BM}$ ) independently inspected the abstracts of the articles gathered from those databases to assess whether the articles were eligible for inclusion according to the criteria. When the full-text versions of the relevant articles were given, both the authors individually assessed them. Whenever a disagreement occurred, the authors resolved it by means of consensus.

\section{Data collection process}

Initially, the first reviewer (NM) extracted the findings of interest and entered them into the data extraction form. Then, the second reviewer (BM) checked those extracted outcomes again. Any disagreement was sorted out by consensus.

\section{Data items}

The essential findings extracted and drawn in all the eligible clinical trials consisted of the following: 1) items associated with assessment of the study quality; 2) crucial basic characteristics of the included subjects, diagnostic criteria, study design for each study, and exclusion and inclusion criteria; 3) formulation, dose, and duration for d-MPH administration; and 4) essential data required in the synthesis. If possible, the intent-to-treat outcomes were also included. 


\section{Quality assessment and risk of bias in individual studies}

The internal validity (quality) was assessed by both the reviewers (NM and BM). As noted in the Handbook of Cochrane Collaboration, the risk of bias in each of the studies was assessed by the following means: 1) generation of randomized sequences (selection bias), 2) allocation concealment (selection bias), 3) blinding of participants and personnel (performance bias), 4) blinding of outcome assessment (detection bias), 5) incomplete outcome data (attrition bias), 6) selective reporting (reporting bias), and 7) other sources of bias (other bias). ${ }^{26}$ Additionally, the Jadad scale for reporting RCTs, which is easy to use and contains many important elements shown to correlate with bias and known reliability and external validity, was also applied. ${ }^{27}$

\section{Summary measures}

There were interesting results in this meta-analysis, including those regarding efficacy, acceptability, and tolerability. Efficacious outcomes were measured by the pooled meanendpoint or mean-changed scores of the standardized ADHD rating scales, and the pooled response rates were evaluated by any set of criteria. As followed in previous systematic reviews, acceptability, the portion of early participant withdrawal from the study for any reason (dropout rates) after intervention, ${ }^{28,29}$ was estimated by the overall discontinuation rate in this review. ${ }^{30}$ Similarly, tolerability, the proportion of participants withdrawing from the study due to adverse events, was determined using the discontinuation rate due to adverse events. ${ }^{31,32}$

\section{Statistical analysis}

In a systematic review, it is possible to synthesize the continuous outcome by using the weighted or standardized mean differences (WMDs or SMDs) with a $95 \%$ confidence interval (CI). If the same outcome measurement is applied across clinical studies, the comparison or the combination of those results is reasonably calculated by using the WMD. Conversely, the use of various rating scales becomes the norm across those studies; SMD, no unit, is used to estimate such comparisons or combinations. In this review, the calculation of any continuous outcome was carried out by using either the WMDs or the SMDs, based on whether a similar or dissimilar rating scale was applied across eligible clinical trials. If the standard deviation (SD) of the mean-endpoint or the meanchanged scores for the ADHD rating scales of eligible articles was not found, it was calculated by means of any statistical method or by direct substitution. ${ }^{33}$ The inverse-variance method was also applied for the estimation of the pooled mean-endpoint or mean-changed scores with $95 \%$ CIs.

The dichotomous findings were synthesized by using the relative risks (RRs) with $95 \% \mathrm{CI}$. If the $\mathrm{RR}$ is one, it suggests that there is no difference between the two study groups. If the RR is less than one, it implies that those results are less likely to occur in the experimental group than in the control group. On the other hand, if the RR is more than one, it means that the outcomes are more likely to occur in the experimental group than in the control group. In this review, we used the RRs for comparing the pooled response rates, overall discontinuation rates, and discontinuation rates due to adverse events between the two study groups. All pooled RRs of dichotomous data with $95 \%$ CIs were calculated using the Mantel-Haenszel method.

\section{Synthesis of results}

In a meta-analysis, data can be synthesized using either a fixed effect model or a random effect model. If the eligible clinical study is based on the assumption that there is a common effect size, it is possible to apply the fixed effect model. In contrast to the random effect model, the variations across the studies are ignored in the fixed effect model. Practically, one true effect size appears less likely to occur, whereas the eligible clinical trials resemble each other relatively. For this reason, it is almost impossible to conclude that those studies are exactly identical. Hence, the synthesis of all the outcomes based on the random effect model was carried out in this review.

\section{Statistical software}

In this review, all the outcomes were synthesized using the RevMan 5.1 (The Nordic Cochrane Centre, Copenhagen, Denmark).

\section{Risk of bias across studies}

In a systematic review, a funnel plot can be used for the examination of the publication bias. The bias can be observed by way of a simple graph of the intervention effect, which is evaluated by an individual study against some measure of each study's size or precision. ${ }^{34}$ Wherever possible, a funnel plot was used in this review.

\section{Test of heterogeneity}

As a rule, a test of heterogeneity is necessary while measuring the similarity of the clinical outcomes across studies in a systematic review. We hypothesized that individually included study outcomes did not have the same effect because of the quality of the methodology in each study. For this reason, the 
extent of disparity among the study results was essentially estimated. With regard to the study findings noted in the graphical display and the use of the test of heterogeneity, the study results can be determined in terms of whether it is by chance alone that they have greater differences than would be expected. If $I^{2}$ is $50 \%$ or more, it is concluded that the significance in the result for heterogeneity occurs.

\section{Results}

\section{Study selection}

The 686 citations obtained from searching of the database were gathered (SCOPUS =548 studies, Medline =59 studies, CINAHL $=24$ studies, Cochrane Controlled Trials Register $=34$ studies, ClinicalTrials.gov $=19$ studies, and EU-CTR $=2$ studies) (Figure 1). After eliminating duplicate citations, the 596 citations obtained were thoroughly inspected. When the titles and abstracts of the rest of the citations were assessed, a total of 582 citations had to be removed as they were incompatible with the eligibility criteria. Thereafter, the 14 full-text articles were carefully examined. Two were excluded because one of them was conducted in child and adolescent ADHD with tic comorbidity $^{35}$ and the other was a withdrawal treatment study. ${ }^{36}$ Subsequently, the finally obtained 12 citations on eleven clinical studies were included in this review. ${ }^{14-24,37}$ There were no relevant and unpublished studies that met the inclusion criteria.

\section{Study characteristics}

A total of 1,124 children and adolescents diagnosed with ADHD were included in this review. The study duration of the included RCTs ranged from 3 to 9 weeks. Four studies reported the washout periods ( 2 days to 1 week). ${ }^{14,16,19,21}$ The doses of d-MPH were 2.5-10 mg for single dose and $5-30 \mathrm{mg} / \mathrm{d}$. The baseline characteristics of the eligible studies are displayed in Table 1.

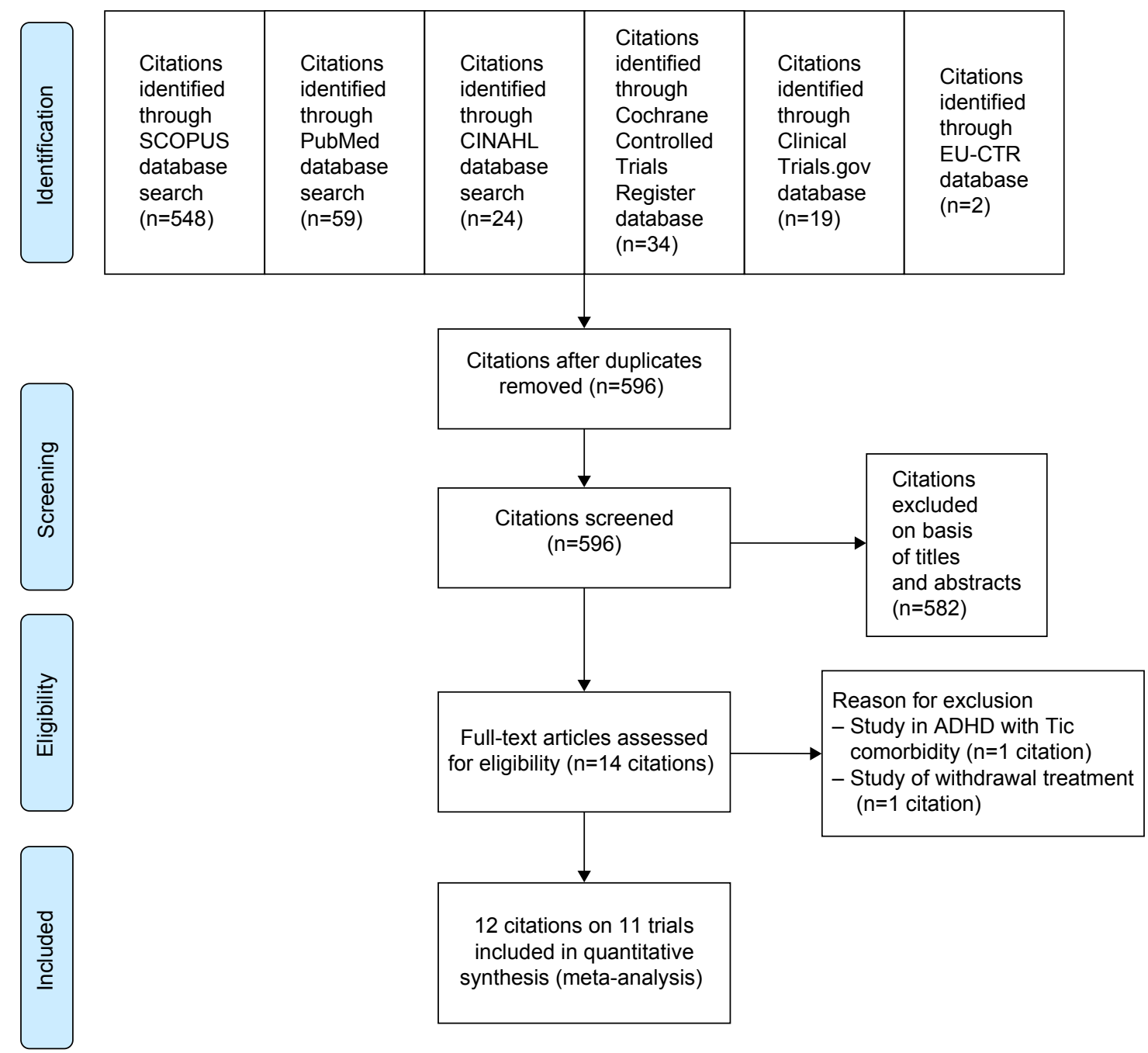

Figure I Flow diagram of meta-analysis search.

Abbreviations: ADHD, attention-deficit hyperactivity disorder; EU-CTR, EU Clinical Trials Register. 


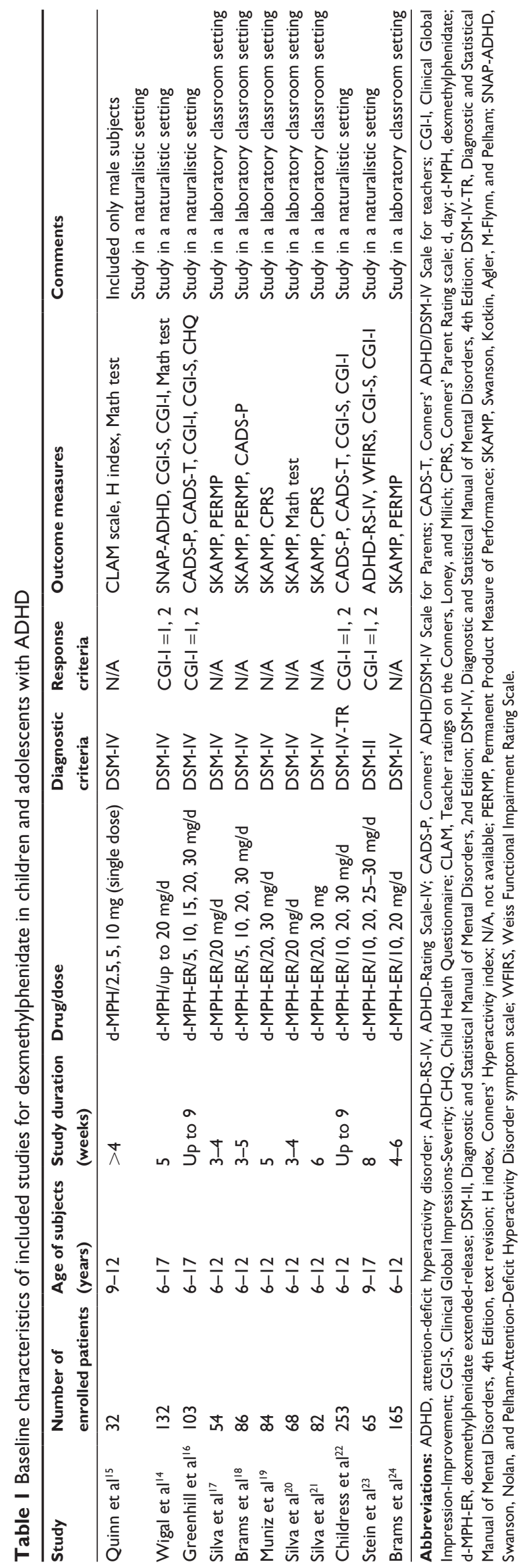

Since the mean-changed or mean-endpoint scores were rated by using different rating scales across the eligible clinical studies, the SMDs were applied for estimating and synthesizing all continuous data. Eight trials ${ }^{16-22,24}$ reported the mean-changed scores, and one ${ }^{15}$ reported the meanendpoint scores. Four studies ${ }^{14,16,22,23}$ reported the response rates. Additionally, six trials ${ }^{14,16-18,20,22}$ reported both overall discontinuation rates and rates of discontinuation due to adverse events.

\section{Risk of bias within studies}

Application of the randomization and double-blind technique was found in all the included trials. The intention-totreat analysis was used in eight studies. ${ }^{14,16,18-22,24}$ Adequate sequence generation of randomization was reported in four clinical trials, ${ }^{17,18,22,24}$ and allocation concealment was reported in three studies. ${ }^{18,22,24}$ The blinding of participants and personnel was clearly identified in nine trials, ${ }^{14,15,17-21,23,24}$ while the blinding of outcome assessment was demonstrated in six studies ${ }^{17-21,24}$ (Table 2). Based on the Jadad scale for reporting RCTs, the quality of each RCT was moderate to good (Table 3).

\section{Results of individual studies}

Eight trials studied ADHD in children and adolescents with several doses of d-MPH; ${ }^{15,16,18,19,21-24}$ hence, the pooled mean-changed score (SD) of the outcome from each study was applied for analyzing and synthesizing. Either the mean-changed score or the mean-endpoint score in the d-MPH-treated group from individually included trials was

Table 2 Summary of risk of bias in clinical controlled trials of dexmethylphenidate in child and adolescent ADHD

\begin{tabular}{|c|c|c|c|c|c|c|c|}
\hline \multirow[t]{2}{*}{ Study } & \multicolumn{7}{|c|}{ Issues of bias } \\
\hline & I & 2 & 3 & 4 & 5 & 6 & 7 \\
\hline Quinn et $\mathrm{al}^{15}$ & $U$ & $U$ & L & $u$ & $U$ & L & L \\
\hline Wigal et al ${ }^{14}$ & $U$ & $U$ & L & $U$ & $\mathrm{~L}$ & $U$ & $\mathrm{~L}$ \\
\hline Greenhill et al ${ }^{16}$ & $U$ & $U$ & $\mathrm{U}$ & $U$ & L & L & $\mathrm{L}$ \\
\hline Silva et al ${ }^{17}$ & $\mathrm{~L}$ & $U$ & $L$ & L & L & $U$ & $\mathrm{~L}$ \\
\hline Brams et $\mathrm{al}^{18}$ & L & $\mathrm{L}$ & L & $\mathrm{L}$ & L & $u$ & $\mathrm{~L}$ \\
\hline Muniz et $\mathrm{al}^{19}$ & $U$ & $U$ & L & L & $U$ & L & $\mathrm{L}$ \\
\hline Silva et $\mathrm{a}^{20}$ & $U$ & $U$ & $\mathrm{~L}$ & L & $\mathrm{L}$ & L & $\mathrm{L}$ \\
\hline Silva et $\mathrm{a}^{21}$ & $U$ & $U$ & L & L & L & L & $\mathrm{L}$ \\
\hline Childress et $\mathrm{a}^{22}$ & $\mathrm{~L}$ & $\mathrm{~L}$ & $u$ & $U$ & L & $U$ & $\mathrm{~L}$ \\
\hline Stein et $\mathrm{a}^{23}$ & $U$ & $U$ & L & $U$ & $U$ & $U$ & L \\
\hline Brams et $\mathrm{al}^{24}$ & $\mathrm{~L}$ & $\mathrm{~L}$ & $\mathrm{~L}$ & $\mathrm{~L}$ & $U$ & $\mathrm{~L}$ & $\mathrm{~L}$ \\
\hline
\end{tabular}

Notes: I, adequate sequence generation of randomization (selection bias); 2, allocation concealment (selection bias); 3 , blinding of participants and personnel (performance bias); 4 , blinding of outcome assessment (detection bias); 5 , incomplete outcome data (attrition bias); 6, selective reporting (reporting bias); 7, other sources of bias (other bias).

Abbreviations: ADHD, attention-deficit hyperactivity disorder; $\mathrm{U}$, unclear; L, low risk of bias. 
Table 3 Summary of quality in clinical trials of dexmethylphenidate in child and adolescent ADHD using the jadad scale for reporting randomized controlled trials

\begin{tabular}{|c|c|c|c|c|}
\hline \multirow[t]{2}{*}{ Study } & \multicolumn{3}{|l|}{ Items } & \multirow[t]{2}{*}{ Total scores } \\
\hline & Randomization & Blinding & Account of all patients & \\
\hline Quinn et al ${ }^{15}$ & 1 & 1 & $\mathrm{I}$ & 3 \\
\hline Wigal et al ${ }^{14}$ & I & 2 & I & 4 \\
\hline Greenhill et al ${ }^{16}$ & I & I & 1 & 3 \\
\hline Silva et al ${ }^{17}$ & 2 & I & 1 & 4 \\
\hline Brams et a ${ }^{18}$ & 2 & 2 & 1 & 5 \\
\hline Muniz et al ${ }^{19}$ & I & 2 & I & 4 \\
\hline Silva et $\mathrm{al}^{20}$ & I & 2 & 1 & 4 \\
\hline Silva et $\mathrm{al}^{21}$ & 1 & 2 & 1 & 4 \\
\hline Childress et $\mathrm{al}^{22}$ & 2 & 1 & I & 4 \\
\hline Stein et $\mathrm{al}^{23}$ & 1 & 2 & I & 4 \\
\hline Brams et $\mathrm{a}^{24}$ & 2 & 2 & I & 5 \\
\hline Mean scores (SD) & $\mathrm{I} .4(0.5)$ & I.6 $(0.5)$ & $\mathrm{I}(0.0)$ & $4(0.6)$ \\
\hline
\end{tabular}

Abbreviations: ADHD, attention-deficit hyperactivity disorder; SD, standard deviation.

significantly higher than that of the placebo-treated group (Figures 2-4). Similarly, the response rate of each study had a greater significance value than that of the placebo-treated group (Figure 5).

\section{Synthesis of results}

\section{Efficacy}

The significance of heterogeneity was found in the pooled mean-changed and mean-endpoint scores of ADHD rating scales for the laboratory school settings. Based on the laboratory school setting, the pooled mean-changed and mean-endpoint scores of child and adolescent ADHD in the d-MPH-treated group were significantly greater than those of the placebo-treated group with SMD $(95 \% \mathrm{CI})$ of -1.2
$(-1.73,-0.67), I^{2}=95 \%$ (Figure 2$)$. Additionally, the meanchanged scores of the ADHD rating scales for teachers in regular classrooms for the d-MPH-treated group also had greater significance than the scores of the placebo-treated group with WMD (95\% CI) of -13.01 (-15.97, -10.05), $I^{2}=0 \%$ (Figure 3). Similarly, the mean-changed scores of the ADHD rating scales for parents in a naturalistic setting for the d-MPH-treated group were significantly greater than the scores of the placebo-treated group with WMD $(95 \% \mathrm{CI})$ of $-12.99(-15.57,-10.42), I^{2}=0 \%$ (Figure 4$)$.

The significant heterogeneity was also identified in the pooled response rate. The pooled response rate of child and adolescent ADHD in the d-MPH-treated groups had a higher significance value than that of the placebo-treated group with

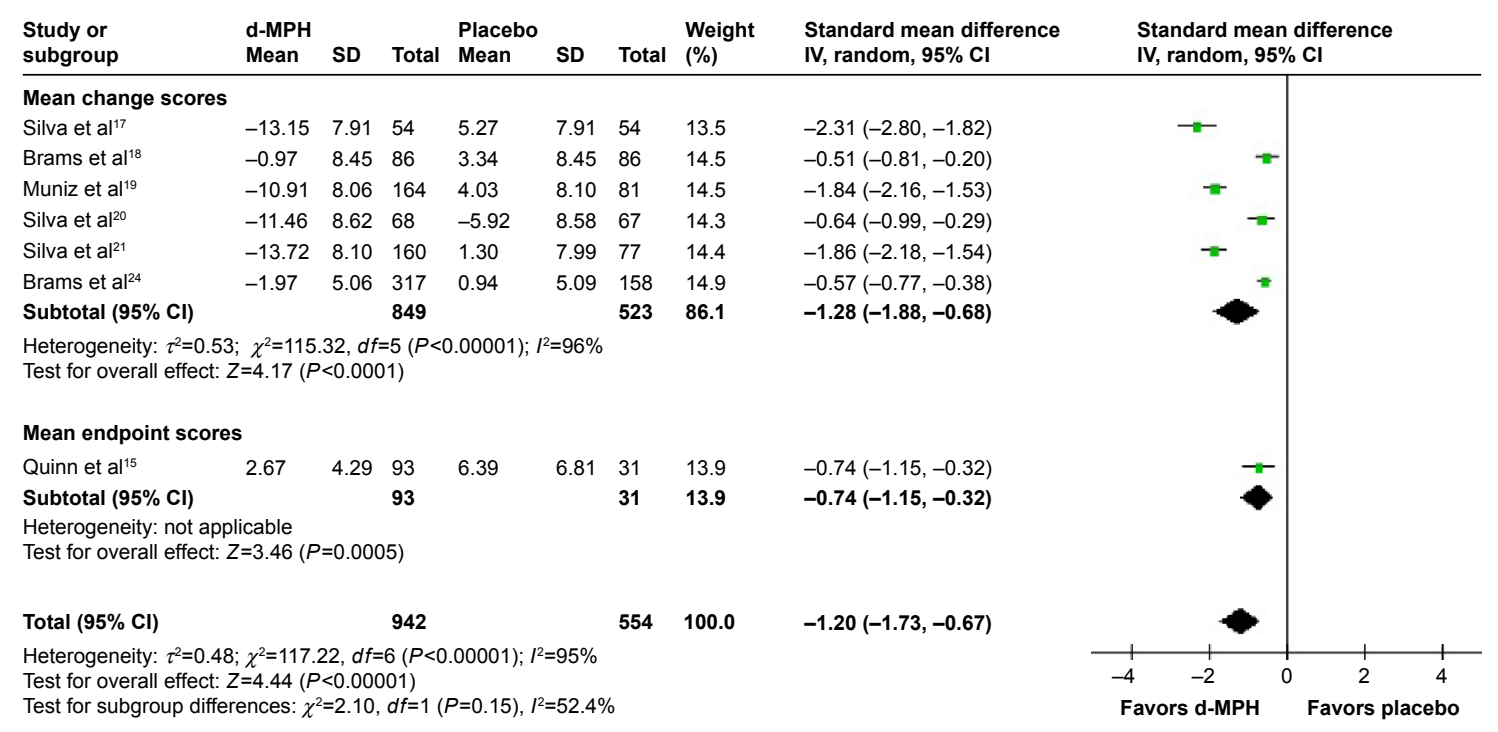

Figure 2 Forest plot comparing mean scores of the ADHD rating scales $(95 \% \mathrm{CII})$ in laboratory school setting for child and adolescent ADHD: dexmethylphenidate vs placebo. Abbreviations: $\mathrm{Cl}$, confidence interval; IV, inverse variance; ADHD, attention-deficit hyperactivity disorder; d-MPH, dexmethylphenidate; SD, standard deviation. 


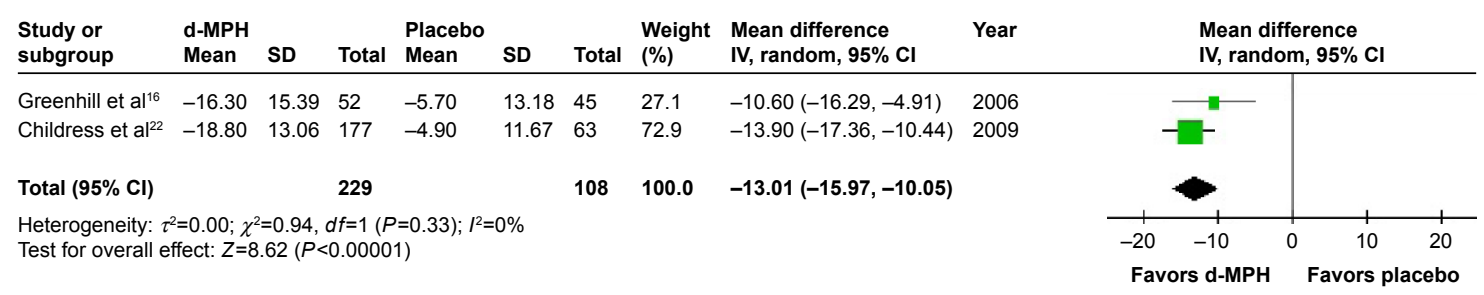

Figure 3 Forest plot comparison of mean-changed scores of ADHD rating scales $(95 \% \mathrm{Cl})$ for teacher rating in regular classrooms for child and adolescent ADHD: dexmethylphenidate vs placebo.

Abbreviations: $\mathrm{Cl}$, confidence interval; IV, inverse variance; ADHD, attention-deficit hyperactivity disorder; d-MPH, dexmethylphenidate; SD, standard deviation.

RR (95\% CI) of $3.10(2.19,4.38), I^{2}=25 \%$ (Figure 5). The pooled response rates of the d-MPH-treated groups and the placebo-treated groups were $60 \%$ and $19 \%$, respectively. According to the pooled response rate, the number needed to treat (NNT) $(95 \% \mathrm{CI})$ was $2.50(2.23,3.07)$.

\section{Discontinuation rates}

No significant heterogeneity was present in either of the pooled discontinuation rates. The pooled overall discontinuation rates in child and adolescent ADHD of the d-MPH-treated groups and the placebo-treated groups were not significantly different with RR $(95 \% \mathrm{CI})$ of $0.72(0.40$, $1.30), I^{2}=14 \%$. The pooled discontinuation rates due to adverse events of the two groups also showed no significant difference with RR $(95 \% \mathrm{CI})$ of $0.74(0.19,2.93), I^{2}=2 \%$.

\section{Risk of bias across studies}

Upon visual inspection of the funnel plot display of SMDs, it was clear that there was no evidence of publication bias since no asymmetry was found (Figure 6).

\section{Discussion}

According to the findings from this review, d-MPH is effective in the treatment of children and adolescents who have been diagnosed with ADHD. In the laboratory school setting, the pooled outcome measure of the mean-changed scores and the mean-endpoint scores of the SKAMP-Combined score were significantly superior to the score of the placebo. The doses of d-MPH in those included studies were in the range of $5-30 \mathrm{mg} / \mathrm{d}$ or $2.5-10 \mathrm{mg}$ (single dose). Additionally, the pooled results of the mean-changed scores of d-MPH $5-30 \mathrm{mg} / \mathrm{d}$, rated by teachers in regular classrooms, were significantly superior to the results given by the placebo. Similarly, the results rated by parents in a naturalistic setting were in the same range. Considering the pooled response rate, the NNT of three suggests that one in every three patients with ADHD will have an advantage from d-MPH treatment.

The efficacy of d-MPH as presented in this review was consistent with that noted in the previous studies of stimulants in ADHD. Several studies indicated the efficacy of methylphenidate (MPH), ${ }^{11,12,38}$ mixed amphetamine salts extended release (Adderall XR), ${ }^{39}$ and lisdexamfetamine..$^{40,41}$ Similarly, the results of this review were the same as those of nonstimulants such as bupropion. ${ }^{5}$ Just like other stimulants, the efficacy of d-MPH is possible as a result of blocking the reuptake of norepinephrine and dopamine. ${ }^{42}$

Based on overall discontinuation, the outcomes suggest that the acceptability of the d-MPH treatment was not better than that of the placebo. The results in this review were similar to those of previous studies. Recent reviews of stimulants such as lisdexamfetamine in ADHD indicate that the acceptability between the active agent and the placebo was comparable. ${ }^{40,41}$ Based on the discontinuous rate due to adverse events, the tolerability of d-MPH was comparable to that of the placebo. Similar findings have been observed in recent systematic reviews of lisdexamfetamine in children and adolescents with ADHD. ${ }^{41}$

There are a few noteworthy limitations of this metaanalysis. First, although there were eleven studies included

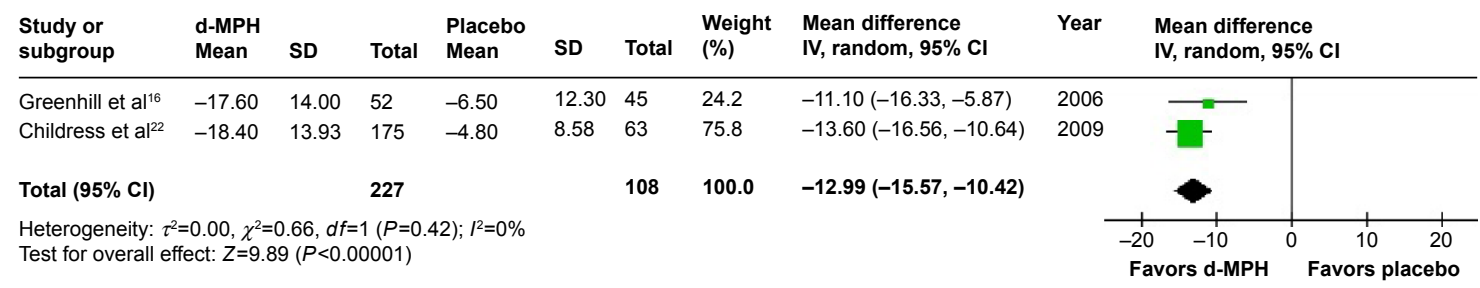

Figure 4 Forest plot of comparison of mean-changed scores of the ADHD rating scales $(95 \% \mathrm{Cl})$ for for parent rating in child and adolescent $A D H D$ : dexmethylphenidate vs placebo.

Abbreviations: $\mathrm{Cl}$, confidence interval; IV, inverse variance; ADHD, attention-deficit hyperactivity disorder; d-MPH, dexmethylphenidate; SD, standard deviation. 


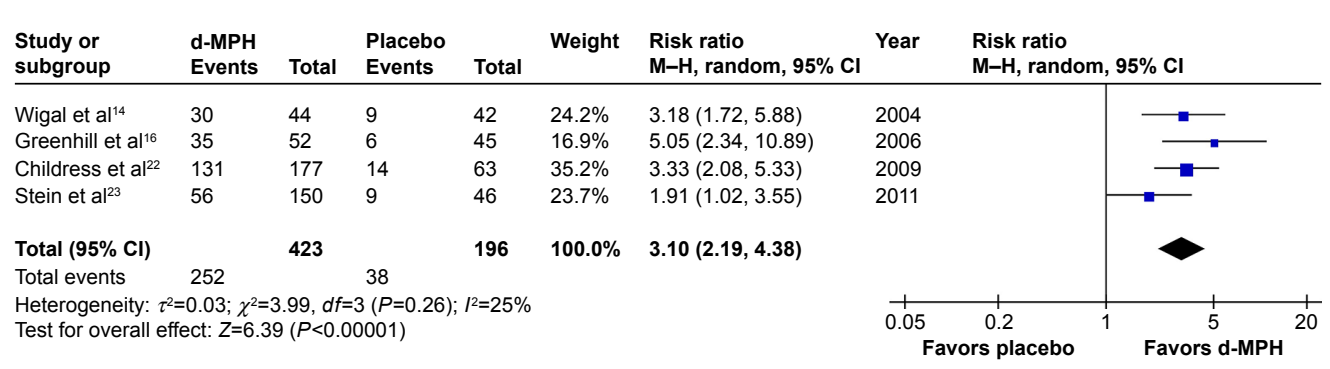

Figure 5 Comparison of relative risks $(95 \% \mathrm{Cl})$ for clinical response rates in child and adolescent ADHD: dexmethylphenidate vs placebo. Abbreviations: ADHD, attention-deficit hyperactivity disorder; $\mathrm{Cl}$, confidence interval; d-MPH, dexmethylphenidate; $\mathrm{M}-\mathrm{H}, \mathrm{Mantel}-\mathrm{H}$ aenszel.

in this review, those were studied in different settings (nine studies in a laboratory school setting and two studies in a naturalistic setting). Hence, the number of the included population in the later studies was limited, which may reduce the potential impact of this review. Second, the significances of heterogeneity noted in the pooled mean-changed and meanendpoint scores of ADHD rating scales for the laboratory school settings, and pooled response rate may imply that significant dissimilarity of such clinical outcomes across studies occurred in the systematic review. Interpretation and application of those outcomes in clinical practice may be limited. Finally, since all the eligible trials were financially granted by a pharmaceutical company holding the patent of d-MPH, the outcomes would have to be interpreted cautiously.

\section{Conclusion}

According to this review, d-MPH was efficacious in the treatment of children and adolescents diagnosed with ADHD. Additionally, the tolerability of d-MPH was good in those patients. However, the acceptability was no better than that of placebo. Since there were some limitations with regard

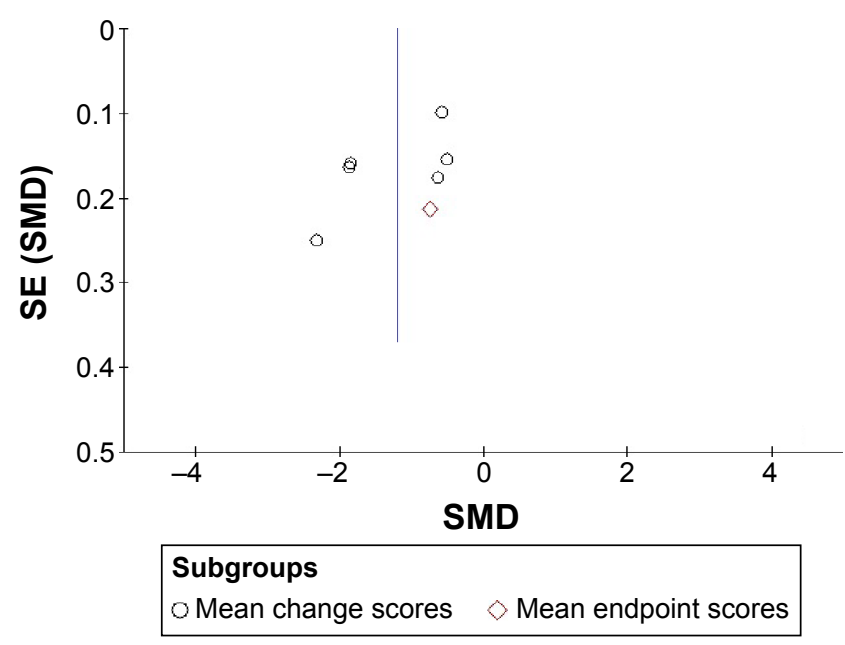

Figure 6 Funnel plot of standardized mean differences of the included studies in child and adolescent ADHD: dexmethylphenidate vs placebo.

Abbreviations: SE, standard error; SMD, standardized mean difference. to the included studies, the interpretation of these outcomes has to be carefully considered. Additional studies should possibly be able to validate these results.

\section{Acknowledgment}

This review received financial support from Chiang Mai University, Thailand.

\section{Author contributions}

All authors contributed toward data analysis, drafting and critically revising the paper, gave final approval of the version to be published, and agree to be accountable for all aspects of the work.

\section{Disclosure}

NM received travel reimbursement from Lundbeck and Pfizer. BM received honoraria and/or travel reimbursement from Lundbeck and Pfizer. PW reports no potential conflicts of interest. SS received honoraria and/or research grants from Janssen-Cilag, Thai-Otsuka, Lundbeck, and AstraZeneca. SL received honoraria and/or travel reimbursement from Janssen-Cilag, Lundbeck, Daiichi Sankyo, and Pfizer. $\mathrm{CC}$ received honoraria and/or travel reimbursement from Janssen-Cilag, GlaxoSmithKline, and Thai-Otsuka. MS received honoraria, consultancy fees, research grants, and/or travel reimbursement from AstraZeneca, GlaxoSmithKline, Pfizer, Janssen-Cilag, Johnson \& Johnson, Lundbeck, ThaiOtsuka, Sanofi-Aventis, and Servier. The authors report no other conflicts of interest in this work.

\section{References}

1. Montiel C, Pena JA, Montiel-Barbero I, Polanczyk G. Prevalence rates of attention deficit/hyperactivity disorder in a school sample of Venezuelan children. Child Psychiatry Hum Dev. 2008;39(3):311-322.

2. Polanczyk G, Rohde LA. Epidemiology of attention-deficit/hyperactivity disorder across the lifespan. Curr Opin Psychiatry. 2007;20(4): 386-392.

3. Catala-Lopez F, Peiro S, Ridao M, Sanfelix-Gimeno G, Genova-Maleras R, Catala MA. Prevalence of attention deficit hyperactivity disorder among children and adolescents in Spain: a systematic review and meta-analysis of epidemiological studies. BMC Psychiatry. 2012;12:168. 
4. Biederman J, Monuteaux MC, Doyle AE, et al. Impact of executive function deficits and attention-deficit/hyperactivity disorder (ADHD) on academic outcomes in children. J Consult Clin Psychol. 2004;72(5):757-766.

5. Maneeton N, Maneeton B, Srisurapanont M, Martin SD. Bupropion for adults with attention-deficit hyperactivity disorder: meta-analysis of randomized, placebo-controlled trials. Psychiatry Clin Neurosci. 2011;65(7):611-617.

6. Maneeton N, Maneeton B, Eurviriyanukul K, Srisurapanont M. Efficacy, tolerability, and acceptability of bupropion for major depressive disorder: a meta-analysis of randomized-controlled trials comparison with venlafaxine. Drug Des Devel Ther. 2013;7:1053-1062.

7. Tanaka Y, Rohde LA, Jin L, Feldman PD, Upadhyaya HP. A metaanalysis of the consistency of atomoxetine treatment effects in pediatric patients with attention-deficit/hyperactivity disorder from 15 clinica trials across four geographic regions. J Child Adolesc Psychopharmacol. 2013;23(4):262-270

8. Nair J, Ehimare U, Beitman BD, Nair SS, Lavin A. Clinical review: evidence-based diagnosis and treatment of ADHD in children. Mo Med. 2006;103(6):617-621.

9. Reddy DS. Current pharmacotherapy of attention deficit hyperactivity disorder. Drugs Today (Barc). 2013;49(10):647-665.

10. Schulz E, Fleischhaker C, Hennighausen K, et al. A randomized, raterblinded, crossover study comparing the clinical efficacy of Ritalin((R)) LA (methylphenidate) treatment in children with attention-deficit hyperactivity disorder under different breakfast conditions over 2 weeks. Atten Defic Hyperact Disord. 2010;2(3):133-138.

11. Murray DW, Childress A, Giblin J, Williamson D, Armstrong R, Starr HL. Effects of OROS methylphenidate on academic, behavioral, and cognitive tasks in children 9 to 12 years of age with attention-deficit/ hyperactivity disorder. Clin Pediatr. 2011;50(4):308-320.

12. Wigal SB, Wigal T, Schuck S, et al. Academic, behavioral, and cognitive effects of OROS(R) methylphenidate on older children with attentiondeficit/hyperactivity disorder. J Child Adolesc Psychopharmacol. 2011; 21(2):121-131.

13. Heal DJ, Pierce DM. Methylphenidate and its isomers: their role in the treatment of attention-deficit hyperactivity disorder using a transdermal delivery system. CNS Drugs. 2006;20(9):713-738.

14. Wigal S, Swanson JM, Feifel D, et al. A double-blind, placebo-controlled trial of dexmethylphenidate hydrochloride and d,1-threo-methylphenidate hydrochloride in children with attention-deficit/hyperactivity disorder. J Am Acad Child Adolesc Psychiatry. 2004;43(11):1406-1414.

15. Quinn D, Wigal S, Swanson J, et al. Comparative pharmacodynamics and plasma concentrations of d-threo-methylphenidate hydrochloride after single doses of d-threo-methylphenidate hydrochloride and d,1threo-methylphenidate hydrochloride in a double-blind, placebo-controlled, crossover laboratory school study in children with attention-deficit/hyperactivity disorder. J Am Acad Child Adoles Psychiatry. 2004;43(11):1422-1429.

16. Greenhill LL, Muniz R, Ball RR, Levine A, Pestreich L, Jiang H. Efficacy and safety of dexmethylphenidate extended-release capsules in children with attention-deficit/hyperactivity disorder. J Am Acad Child Adolesc Psychiatry. 2006;45(7):817-823.

17. Silva RR, Muniz R, Pestreich L, et al. Efficacy and duration of effect of extended-release dexmethylphenidate versus placebo in schoolchildren with attention-deficit/hyperactivity disorder. J Child Adolesc Psychopharmacol. 2006;16(3):239-251.

18. Brams M, Muniz R, Childress A, et al. A randomized, double-blind, crossover study of once-daily dexmethylphenidate in children with attention-deficit hyperactivity disorder: rapid onset of effect. CNS Drugs. 2008;22(8):693-704.

19. Muniz R, Brams M, Mao A, McCague K, Pestreich L, Silva R. Efficacy and safety of extended-release dexmethylphenidate compared with d,1-methylphenidate and placebo in the treatment of children with attention-deficit/hyperactivity disorder: a 12-hour laboratory classroom study. J Child Adolesc Psychopharmacol. 2008;18(3): 248-256.

20. Silva RR, Muniz R, Pestreich L, et al. Dexmethylphenidate extendedrelease capsules in children with attention-deficit/hyperactivity disorder. J Am Acad Child Adolesc Psychiatry. 2008;47(2):199-208.
21. Silva R, Muniz R, McCague K, Childress A, Brams M, Mao A Treatment of children with attention-deficit/hyperactivity disorder: results of a randomized, multicenter, double-blind, crossover study of extended-release dexmethylphenidate and D,L-methylphenidate and placebo in a laboratory classroom setting. Psychopharmacol Bull. 2008; 41(1):19-33.

22. Childress AC, Spencer T, Lopez F, et al. Efficacy and safety of dexmethylphenidate extended-release capsules administered once daily to children with attention-deficit/hyperactivity disorder. J Child Adolesc Psychopharmacol. 2009;19(4):351-361.

23. Stein MA, Waldman ID, Charney E, et al. Dose effects and comparative effectiveness of extended release dexmethylphenidate and mixed amphetamine salts. J Child Adolesc Psychopharmacol. 2011;21(6):581-588.

24. Brams M, Turnbow J, Pestreich L, et al. A randomized, double-blind study of 30 versus $20 \mathrm{mg}$ dexmethylphenidate extended-release in children with attention-deficit/hyperactivity disorder: late-day symptom control. J Clin Psychopharmacol. 2012;32(5):637-644.

25. US Food and Drug Administration, Center for Drug Evaluation and Research. Focalin NDA 021278 approval letter. November 13, 2001. Available from: http://www.accessdata.fda.gov/drugsatfda_docs/ nda/2001/21-278_Focalin_Approv.pdf. Accessed July 29, 2015.

26. Higgins JPT, Altman DG. Assessing risk of bias in included studies. In: Higgins JPT, Green S, editors. Cochrane Handbook for Systematic Reviews of Interventions. Version 5.1.0 (Updated March 2011) ed. The Cochrane Collaboration; 2009.

27. Jadad AR, Moore RA, Carroll D, et al. Assessing the quality of reports of randomized clinical trials: is blinding necessary? Control Clin Trials. 1996;17(1):1-12.

28. Koesters M, Guaiana G, Cipriani A, Becker T, Barbui C. Agomelatine efficacy and acceptability revisited: systematic review and meta-analysis of published and unpublished randomised trials. Br J Psychiatry. 2013; 203(3):179-187.

29. Okumura Y, Ichikura K. Efficacy and acceptability of group cognitive behavioral therapy for depression: a systematic review and metaanalysis. J Affect Disord. 2014;164:155-164.

30. Cipriani A, Furukawa TA, Salanti G, et al. Comparative efficacy and acceptability of 12 new-generation antidepressants: a multipletreatments meta-analysis. Lancet. 2009;373(9665):746-758.

31. Papakostas GI. Tolerability of modern antidepressants. J Clin Psychiatry. 2008;69(Suppl E1):8-13.

32. Baldwin D, Woods R, Lawson R, Taylor D. Efficacy of drug treatments for generalised anxiety disorder: systematic review and meta-analysis. BMJ. 2011;342:d1199.

33. Wiebe N, Vandermeer B, Platt RW, Klassen TP, Moher D, Barrowman NJ. A systematic review identifies a lack of standardization in methods for handling missing variance data. J Clin Epidemiol. 2006;59(4):342-353.

34. Sterne JAC, Egger M, Moher D. Addressing reporting biases. In: Higgins JPT, Green S, editors. Cochrane Handbook for Systematic Reviews of Interventions. Version 5.1.0 (Updated March 2011). The Cochrane Collaboration; 2009. Available from: http://www.cochranehandbook.org. Accessed September 21, 2015.

35. Lyon GJ, Samar SM, Conelea C, et al. Testing tic suppression: comparing the effects of dexmethylphenidate to no medication in children and adolescents with attention-deficit/hyperactivity disorder and Tourette's disorder. J Child Adolesc Psychopharmacol. 2010;20(4):283-289.

36. Arnold LE, Lindsay RL, Conners CK, et al. A double-blind, placebocontrolled withdrawal trial of dexmethylphenidate hydrochloride in children with attention deficit hyperactivity disorder. J Child Adolesc Psychopharmacol. 2004;14(4):542-554.

37. Silva RR, Brams M, McCague K, Pestreich L, Muniz R. Extended-release dexmethylphenidate $30 \mathrm{mg} / \mathrm{d}$ versus $20 \mathrm{mg} / \mathrm{d}$ : duration of attention, behavior, and performance benefits in children with attention-deficit/ hyperactivity disorder. Clin Neuropharmacol. 2013;36(4):117-121.

38. Schulz E, Fleischhaker C, Hennighausen K, et al. A double-blind, randomized, placebo/active controlled crossover evaluation of the efficacy and safety of Ritalin (R) LA in children with attention-deficit/ hyperactivity disorder in a laboratory classroom setting. JChild Adolesc Psychopharmacol. 2010;20(5):377-385. 
39. Spencer TJ, Wilens TE, Biederman J, Weisler RH, Read SC, Pratt R. Efficacy and safety of mixed amphetamine salts extended release (Adderall XR) in the management of attention-deficit/hyperactivity disorder in adolescent patients: a 4-week, randomized, double-blind, placebo-controlled, parallel-group study. Clin Ther. 2006;28(2): 266-279.

40. Maneeton N, Maneeton B, Suttajit S, Reungyos J, Srisurapanont M, Martin SD. Exploratory meta-analysis on lisdexamfetamine versus placebo in adult ADHD. Drug Des Devel Ther. 2014;8:1685-1693.
41. Maneeton B, Maneeton N, Likhitsathian S, et al. Comparative efficacy, acceptability, and tolerability of lisdexamfetamine in child and adolescent ADHD: a meta-analysis of randomized, controlled trials. Drug Des Devel Ther. 2015;9:1927-1936.

42. Dexmethylphenidate - Novartis/Celgene. Focalin, D-MPH, D-methylphenidate hydrochloride, D-methylphenidate, dexmethylphenidate, dexmethylphenidate hydrochloride. Drugs $R D$. 2002;3(4):279-282.

\section{Publish your work in this journal}

Neuropsychiatric Disease and Treatment is an international, peerreviewed journal of clinical therapeutics and pharmacology focusing on concise rapid reporting of clinical or pre-clinical studies on a range of neuropsychiatric and neurological disorders. This journal is indexed on PubMed Central, the 'PsycINFO' database and CAS, and is the official journal of The International Neuropsychiatric Association (INA). The manuscript management system is completely online and includes a very quick and fair peer-review system, which is all easy to use. Visit http://www.dovepress.com/testimonials.php to read real quotes from published authors.

Submit your manuscript here: http://www.dovepress.com/neuropsychiatric-disease-and-treatment-journal 